\title{
Radiology of homograft aortic valves ${ }^{1}$
}

\author{
P. W. T. BRANDT, A. H. G. R OCHE, B. G. BARRATT-BOYES, \\ A ND J.B. LOWE
}

From Green Lane Hospital, Auckland, New Zealand

\begin{abstract}
A consecutive series of 93 patients had homograft aortic valve replacement at Green Lane Hospital over a six-month period. Except for 12 assessed at one or two months, the 85 survivors were examined at three months and the clinical degree of aortic incompetence was recorded. Thirty-four of the patients did not proceed to aortography for reasons unrelated to the state of the homograft valve. Fifty-one patients were submitted to cine aortography, using a technique designed to permit a radiological assessment of the degree of aortic incompetence and to reveal details of the anatomy of the homograft valve. Following a brief review of the surgical technique of homograft aortic valve insertion, the radiological anatomy of homograft aortic valves and the mechanism of peripheral aortic incompetence in this situation are described. A radiological method of grading aortic incompetence by cine aortography is presented and the results in the 51 patients are described. The incidence of peripheral space filling and incompetence was considerably lower in the second half of the consecutive series, apparently due to a modification of the surgical technique, namely, the addition of vertical mattress sutures beneath the valve commissures to promote closure of the potential peripheral space. In the whole series of 51 patients, $71 \%$ had no significant aortic incompetence. In the latter half of the study after the vertical mattress sutures had been introduced, $84 \%$ had no significant incompetence. These results were from operations by a total of six surgeons. A smaller series of patients operated on by one surgeon using vertical mattress sutures was studied by the same methods. Eighteen of 19 patients $(95 \%)$ had no significant incompetence. Good agreement was found between the radiological and clinical assessment of aortic incompetence, indicating that standard clinical methods can be applied to patients with homograft aortic valve incompetence.
\end{abstract}

Homograft aortic valve replacement has been the treatment of choice for severe aortic valve disease at Green Lane Hospital since 1962 (Barratt-Boyes, 1964). The method is also in use in other clinics in selected patients (Ross, 1966 ; Hoeksema, Titus, Giuliani, and Kirklin, 1966; Bigelow, Trimble, Aldridge, Bedard, Spratt, and Lansdown, 1967 ; Malm, Bowman, Harris, and Kowalik, 1967; Nelson, Mohri, Winterscheid, Dillard, and Merendino, 1967).

Follow-up studies from this hospital (BarrattBoyes, 1964 ; Barratt-Boyes, Lowe, Cole, and Kelly, 1965 ; Barratt-Boyes, 1967) have been reported, including the incidence of aortic incompetence assessed clinically. Those patients who have required second homograft valve replacements for important residual or recurrent aortic incompetence have usually had cusp rupture or peripheral suture line leak, although occasionally either malposition of the leaflets or bacterial endo-

1This study has been supported by a grant from the Auckland Medical Research Foundation carditis has been the cause (Barratt-Boyes, Roche, and Cole, 1968). The mechanism of homograft valve incompetence in surviving patients with lesions of lesser severity was unknown. Although there was no reason to doubt the reliability of the clinical assessment of incompetence following homograft aortic valve replacement, a radiological assessment of a postoperative group of patients was thought to be desirable to assess the incidence of aortic incompetence by this technique, to study the anatomy of the homograft valves, and to determine the mechanism of incompetence when present.

\section{MATERIAL AND METHOD}

All available patients who had had homograft aortic valve replacement between 28 September 1966 and 25 May 1967 were reviewed postoperatively at three months or later, this time interval being chosen because of the clinical observation that an aortic diastolic murmur rarely appears after three months. The clinical grade of aortic incompetence when present 
was recorded and a radiological study was undertaken on the following day. The chief criteria used in the clinical grading are summarized in Table I.

T A B L E I

CRITERIA USED IN CLINICAL GRADING

\begin{tabular}{|c|c|c|}
\hline $\begin{array}{l}\text { Grade of } \\
\text { Aortic In- } \\
\text { competence }\end{array}$ & $\begin{array}{l}\text { Main Clinical } \\
\text { Features }\end{array}$ & $\begin{array}{c}\text { Main Radiological } \\
\text { Features }\end{array}$ \\
\hline 0 (Absent) & $\begin{array}{l}\text { Normal pulse and } \\
\text { blood pressure. No } \\
\text { aortic } \\
\text { murmur }\end{array}$ & $\begin{array}{l}\text { No contrast seen to pass the } \\
\text { valve or 'closing whiff' } \\
\text { only }\end{array}$ \\
\hline 1 (Trivial) & $\begin{array}{l}\text { Normal pulse and } \\
\text { blood } \\
\text { Aortic } \\
\text { muressure. } \\
\text { diastolic }\end{array}$ & $\begin{array}{l}\text { No outlining of left ventricu- } \\
\text { lar cavity. Contrast } \\
\text { usually confined to out- } \\
\text { flow tract }\end{array}$ \\
\hline 2 (Mild) & $\begin{array}{l}\text { Slightly jerky pulse. } \\
\text { Pulse pressure less } \\
\text { than half systolic } \\
\text { pressure }\end{array}$ & $\begin{array}{l}\text { Left ventricle outlined } \\
\text { faintly, transiently or } \\
\text { slowly }\end{array}$ \\
\hline 3 (Moderate) & $\begin{array}{l}\text { Jerky or collapsing } \\
\text { pulse. Widening of } \\
\text { pulse pressure }\end{array}$ & $\begin{array}{l}\text { Rapid outlining of left ven- } \\
\text { tricle. Aortic-ventricular } \\
\text { densities equal after three } \\
\text { diastoles. Contrast elim- } \\
\text { inated by } 10 \mathrm{sec} \text {. }\end{array}$ \\
\hline 4 (Severe) & $\begin{array}{l}\text { Frankly collapsing or } \\
\text { water hammer pulse }\end{array}$ & $\begin{array}{l}\text { Rapid outlining of left ven- } \\
\text { tricle. Aortic-ventricular } \\
\text { densities equal within } \\
\text { three diastoles. Contrast } \\
\text { persists beyond } 10 \mathrm{sec} \text {. }\end{array}$ \\
\hline
\end{tabular}

Among the 93 patients who underwent homograft aortic valve replacement in the period under review, there were seven hospital deaths and one late death. None was due to aortic incompetence. Of the 85 survivors at three months, 51 were submitted to aortography. The reasons for excluding 34 patients from the aortographic series are listed in Table II, and had

\section{T A B L E I I}

PATIENTS EXCLUDED FROM CINE STUDY

\begin{tabular}{|c|c|c|c|c|c|c|}
\hline \multicolumn{6}{|c|}{ Reason } & $\frac{\text { No. }}{10}$ \\
\hline $\begin{array}{l}\text { Overseas . . . . } \\
\text { Prosthetic mitral valve (antico } \\
\text { Age over } 70 \quad \ldots \\
\text { Multiple previous studies } \\
\text { Severe coronary disease } \\
\text { Refused study . } \quad . \\
\text { Psychologically unfit } \ldots \\
\text { Recurrent ventricular fibrillati } \\
\text { Pre-op. aortic dissection } \\
\text { Possible aortic medionecrosis }\end{array}$ & $\begin{array}{c}\ldots \\
\text { agu } \\
\ldots \\
\ldots \\
\ldots \\
\ldots \\
\text { on } \\
\ldots \\
\cdots\end{array}$ & $\begin{array}{c}\ldots \\
\text { ts) } \\
\cdots \\
\cdots \\
\cdots \\
\ldots \\
\text { t-op. } \\
\cdots \\
\cdots\end{array}$ & $\begin{array}{l}\ldots \\
\cdots \\
\cdots \\
\cdots \\
\cdots \\
\cdots \\
\ldots \\
\cdots \\
\cdots\end{array}$ & $\begin{array}{l}\cdots \\
\cdots \\
\cdots \\
\cdots \\
\cdots \\
\cdots \\
\cdots \\
\cdots \\
\cdots\end{array}$ & $\begin{array}{l}\ldots \\
\ldots \\
\cdots \\
\cdots \\
\cdots \\
\cdots \\
\cdots \\
\cdots \\
\cdots\end{array}$ & $\begin{array}{r}10 \\
8 \\
4 \\
2 \\
2 \\
3 \\
2 \\
1 \\
1 \\
1\end{array}$ \\
\hline Possible aortic medionecrosis & & & & Total & $\cdots$ & 34 \\
\hline
\end{tabular}

no bearing on the state of the homograft aortic valve. In fact, the clinical assessment of aortic valve function in the excluded group indicated a somewhat lower incidence of incompetence in these patients than in those studied angiographically (Table III). Eight of the excluded patients were, however, assessed at one month, and four at two months rather than three.
T A B L E I I I

INCOMPETENCE IN PATIENTS STUDIED AND NOT

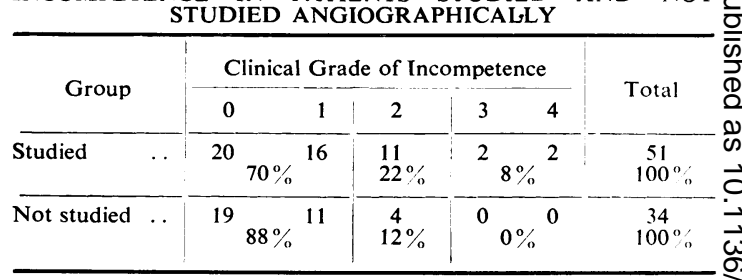

RADIOLOGICAL TECHNIQUE Nearly all patients were catheterized by the percutaneous method from the right femoral artery, using a No. 7 Gensini type N catheter (with end and side holes). A few had brachial $\overrightarrow{\mathrm{N}}$ arteriotomy, and an N.I.H. catheter was then used with side holes only. The catheter tip was placed a short distance above the homograft aortic valve and the aortic pressure was recorded. Two $40-\mathrm{ml}$. injections of $85 \%$ Hypaque were given, using a Talley $\frac{0}{\widehat{D}}$ pressure injection apparatus, at a speed of approxi- $\supset$ mately 20-25 ml. per second. Aortograms were re- $\overrightarrow{0}$ corded on $35 \mathrm{~mm}$. cine film at 60-70 frames per second, the first from a 9-in. image intensifier in right anterior oblique (RAO) projection with a little geometric enlargement, the left ventricle and about half the ascending aorta being included in the field (Fig. $\bar{O}$ 1a). The second injection was recorded from a 6-in. ڤ્ image intensifier in lateral projection, using a little $\underset{\mathbb{Q}}{\mathbb{2}}$ geometric enlargement so that the aortic root and left ventricular outflow tract virtually filled the cine frame (Fig. 1b). The 9-in. intensifier (RAO) view was used to assess the degree of aortic incompetence. The 6-in. intensifier (lateral) view gave more precise ana-? tomical detail of the valve itself in another projection and had the additional advantage that there were no 0 confusing hilar shadows overlying the aortic root. No $\stackrel{x}{x}$ attempt was made to pass the catheter across the homograft aortic valve, as aortic stenosis is not a problem in the early postoperative period (BarrattBoyes et al., 1965).

RADIOLOGICAL CRITERIA The criteria used in assessing the degree of aortic incompetence radiologically are $\frac{D}{O}$ summarized in Table I. In a few patients, a small puff of contrast occasionally entered the left ventri- N cular outflow tract as the valve leaflets closed, without further passage of contrast during the remainder $\mathbb{N}$ of diastole. This phenomenon was regarded as a 'closing whiff' and not incompetence and was not $\sigma$ usually visible in the 9 -in. intensifier RAO view. Occasionally a minute leak was seen throughout dia- $\frac{0}{\mathrm{C}}$ stole in the 6-in. intensifier view; in this case it was $\mathbb{E}$ classified as trivial aortic incompetence, even though : invisible in the 9 -in. intensifier view. Trivial aortic $\frac{7}{7}$ incompetence by our definition did not give even transitory outlining of the left ventricular cavity (Fig. 1a). If the cavity outlined faintly, transiently or slowly $\overrightarrow{\mathbb{Q}}$ through the cine 'run' so that aortic and left ventricular densities did not become equal until contrast 


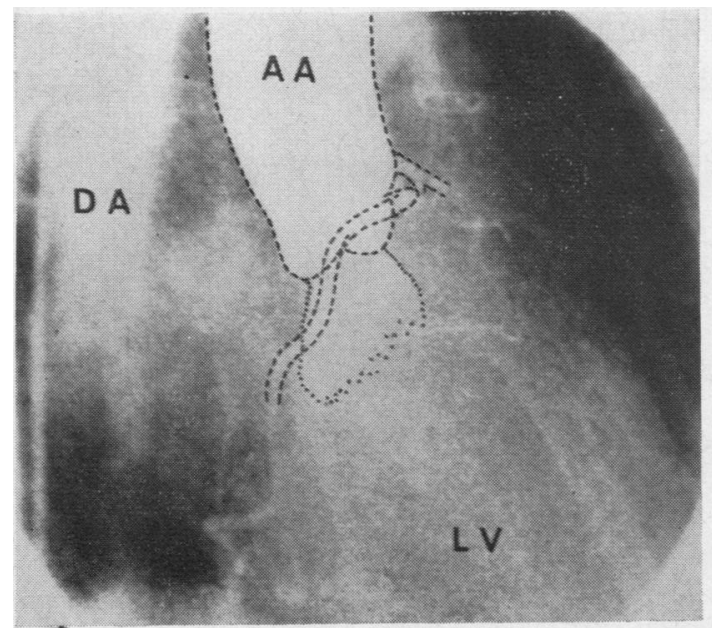

(a)

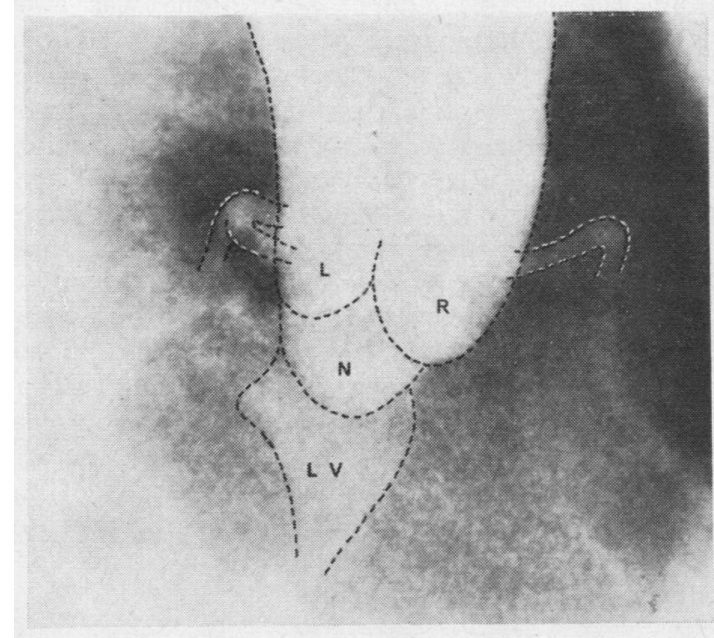

(b)

FIG. 1. Trivial aortic incompetence without peripheral space filling: (a) Diastolic RAO cine frame (9-in. intensifier). At end of third diastole faint outline of outflow tract but no outlining of left ventricular cavity $(L V)$. Ascending aorta $(A A)$ densely filled and descending aorta $(D A)$ also filled. (b) Diastolic lateral cine frame (6-in. intensifier). No peripheral space filling. Central leak outlines left ventricular outflow tract $(L V)$.

was almost eliminated from the region (usually late in the 'run' at about 6 seconds), the degree was mild (Fig. 2). Moderate aortic incompetence was present when the left ventricular cavity outlined rapidly, but the density in the left ventricle did not equal that in the aorta until after three diastolic periods (Fig. 3) and the contrast was eliminated from the field by 10 seconds. Aortic incompetence was severe when there was rapid filling of the left ventricle and density in the left ventricle equalled that in the aorta within three diastoles (Fig. 4a). Contrast persisted for at least 10 seconds.

\section{ANATOMY OF HOMOGRAFT AORTIC VALVES}

SURGICAL TECHNIQUE The anatomy of homograft aortic valves is related to the method of insertion (Barratt-Boyes, 1965). The patient's diseased valve

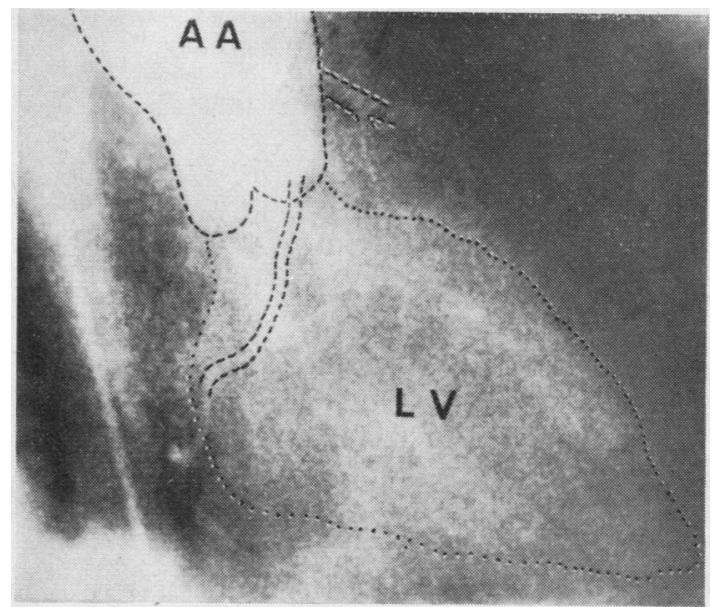

FIG. 2. Mild artic incompetence. Diastolic $R A O$ cine frame. At end of third diastole faint outlining of left ventricle $(L V)$ which soon cleared. Contrast density in ventricle did not approach that in ascending aorta $(A A)$.

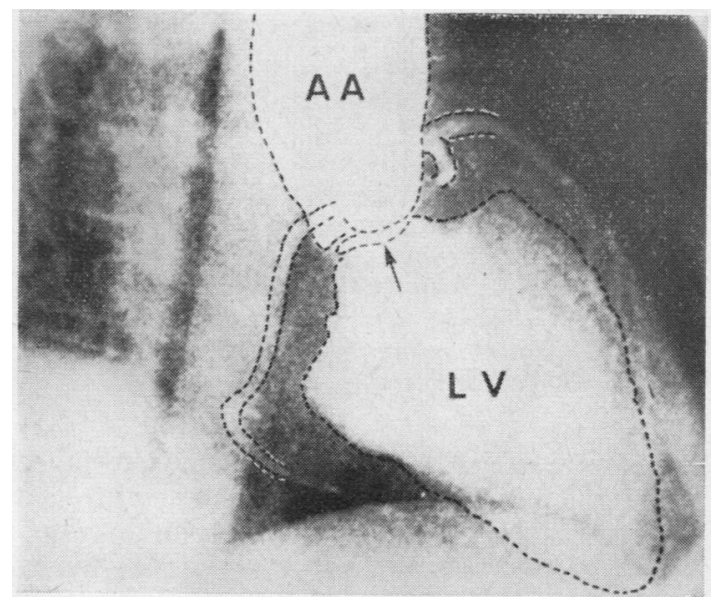

FIG. 3. Moderate aortic incompetence. Diastolic $R A O$ cine frame. At end of third diastole, left ventricle $(L V)$ is clearly outlined but density did not equal that in ascending aorta $(A A)$ until end of fifth diastole. Contrast was eliminated in 10 seconds. Peripheral space filling is visible (arrow). 


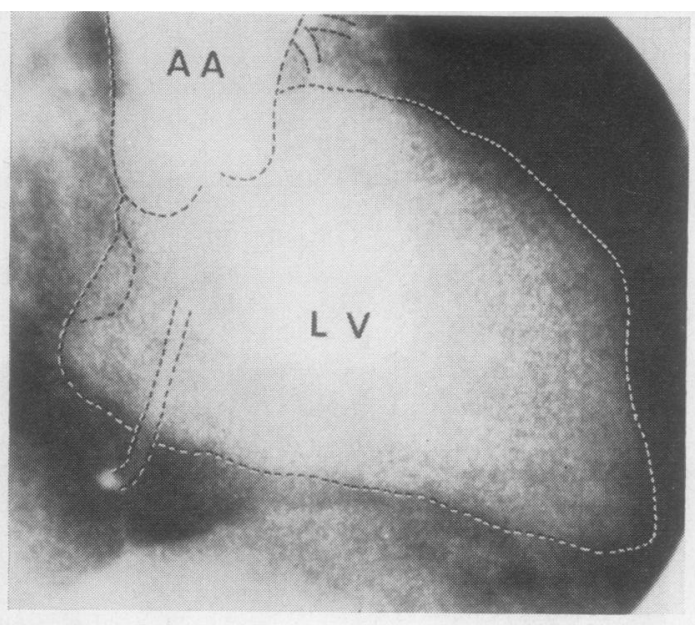

(a)

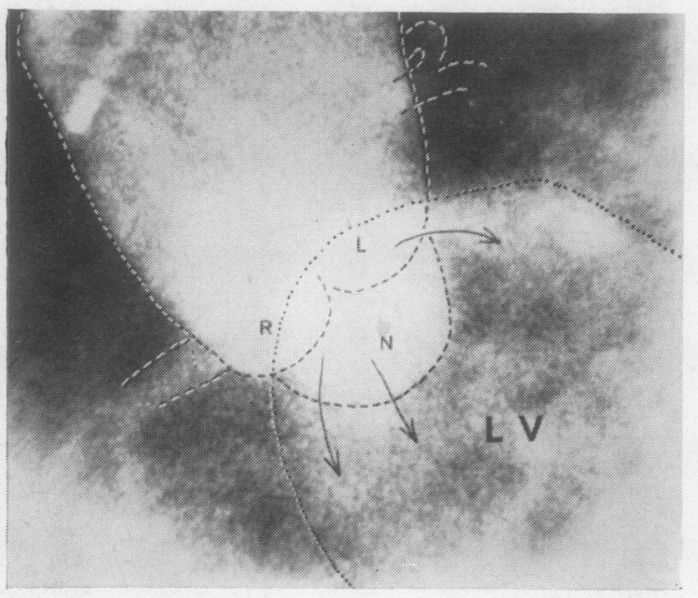

(b)

FIG. 4. Severe aortic incompetence (cusp rupture): (a) Diastolic RAO cine frame. At end of third diastole contrast density in left ventricle ( $L V)$ equalled that in ascending aorta $(A A)$. Contrast persisted beyond 10 seconds. $(b)$ Diastolic lateral (6-in. intensifier) cine frame. Severe leak (arrows) without peripheral space filling.

cusps were excised and, if the patient's aortic root was too large for the available homograft valve, it was reduced in size (tailored) by excising a wedge of tissue from the non-coronary sinus and aortic ring. The trimmed homograft valve was secured in the subcoronary position by two suture lines (Fig. 5). The lower suture line was first completed, with the homograft valve inverted in the left ventricular outflow tract, and attached the lower circular perimeter of the valve to the out-

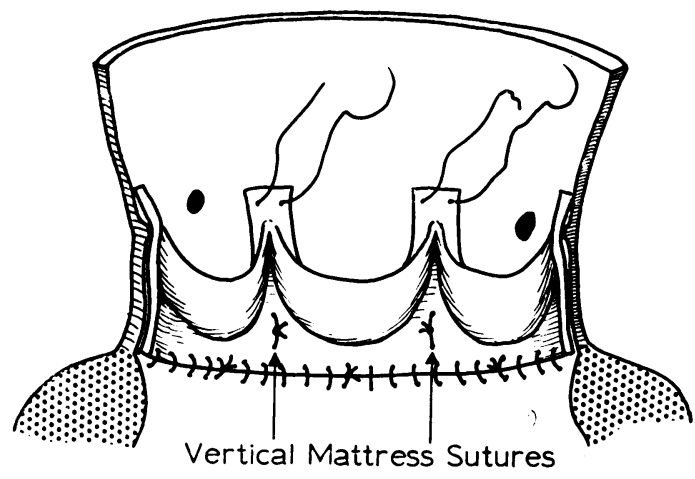

FIG. 5. The surgical technique of homograft aortic valve $\vec{N}$ insertion. For description, see text.

flow tract of the host. The three buttresses of the $\bar{z}$ homograft aortic wall supporting the commissures $\frac{2}{3}$ were then attached to the aortic wall of the host $\Im$ and the scalloped upper suture line was com- $\vec{\oplus}$ pleted. The homograft valve was inserted with 8 approximately $120^{\circ}$ anticlockwise rotation, so that most of the muscular portion of the graft valve ring was sutured to the fibrous part of the host outflow tract (the base of the anterior mitral leaflet) beneath the left sinus of Valsalva. It can $\frac{\circ}{\mathcal{D}}$ be appreciated that a potential peripheral space $\varrho$ exists between the host aortic wall and the homo- $\overrightarrow{0}$ graft tissue (between the upper and lower suture 3 lines), and through this space peripheral aortic incompetence may take place. About halfway through the period of the study, the operation was modified by adding three vertical mattress sutures $\frac{0}{2}$ placed directly beneath the commissures of the $\times$ homograft leaflets (Fig. 5) to obliterate the major $\frac{5}{3}$ portion of the potential peripheral space and divide it into compartments.

RADIOLOGICAL APPEARANCES When there was no을 peripheral space filling, a homograft aortic valve $D$ was difficult to distinguish from a normal aortic valve (Fig. 6a, b). Not infrequently a slight ridge $N$ was seen in the noncoronary sinus of Valsalva, profiled in the RAO view (Fig. 7a, b). If this ridge $\stackrel{N}{ }$ was large, it occasionally produced a double contour of the noncoronary sinus in the lateral view, which could have been mistaken for peripheralo

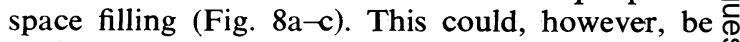
excluded by correlation of the two views. Such a $\stackrel{\infty}{\rightarrow}$ ridge was less commonly seen in the other sinuses 0 and probably resulted from a less extensive re- $\stackrel{0}{\circ}$

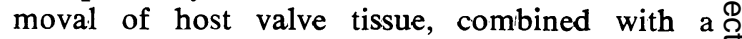
slightly closer approximation of upper and lower $\mathbb{\mathbb { Q }}$ suture lines in this region, to avoid risk of damage to the bundle of His. 


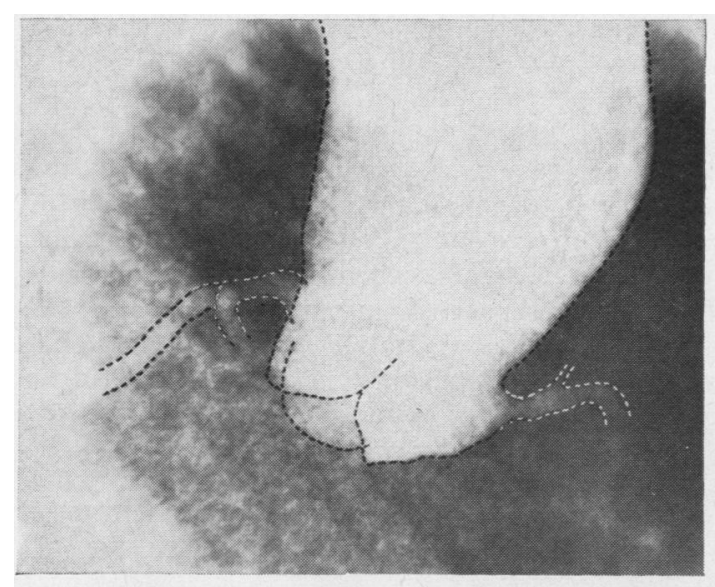

(a)

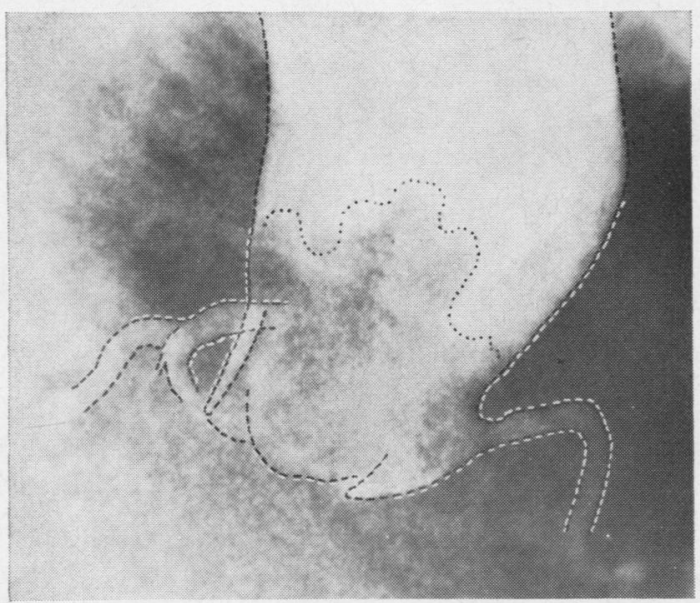

(b)

FIG. 6. Lateral view (6-in. intensifier) of fully competent valve: (a) Diastolic frame. Right coronary cusp is as low as non-coronary cusp due to an inclined long axis of aortic root. (b) Systolic frame. The cusps are normally flexible and allow a full-width bolus of non-opaque blood to displace contrast in aortic root.

The three aortic cusps were usually in normal relative position. Renaming them according to the host sinuses of Valsalva, the left coronary cusp was highest, the noncoronary the lowest, and the right coronary cusp intermediate (Figs $1 \mathrm{~b}, 7 \mathrm{a}$, and 8c). In three patients the right coronary cusp was at the same level as or lower than the noncoronary cusp. This was accompanied by mild aortic incompetence in one, trivial in another (Fig. 9), and a competent valve in the third (Fig. 6a. b). The relative positions of the cusps seemed to be related more often to variation in the orientation of the long axis of the aortic root than to variation in surgical placement of the valve. The opening of the noncoronary sinus of Valsalva in one patient was somewhat narrowed, leading to less dense contrast filling of this sinus (Fig. 10). This patient

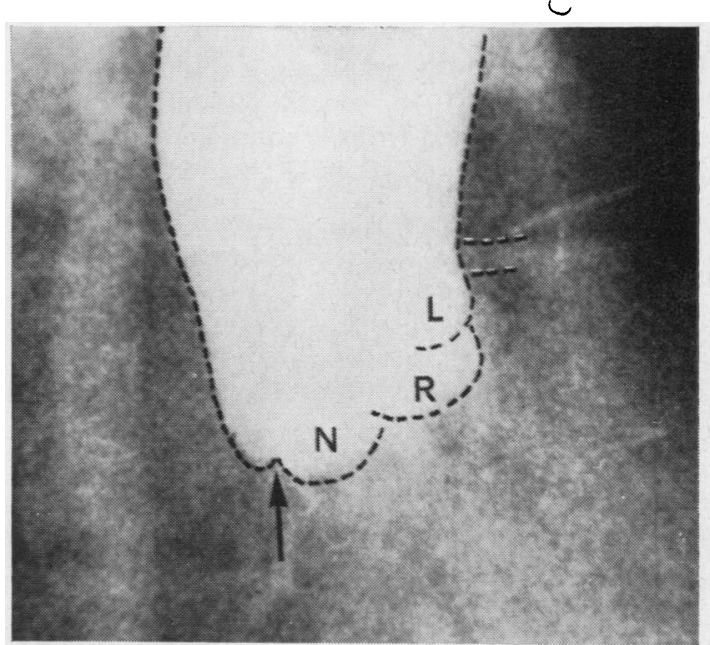

(a)

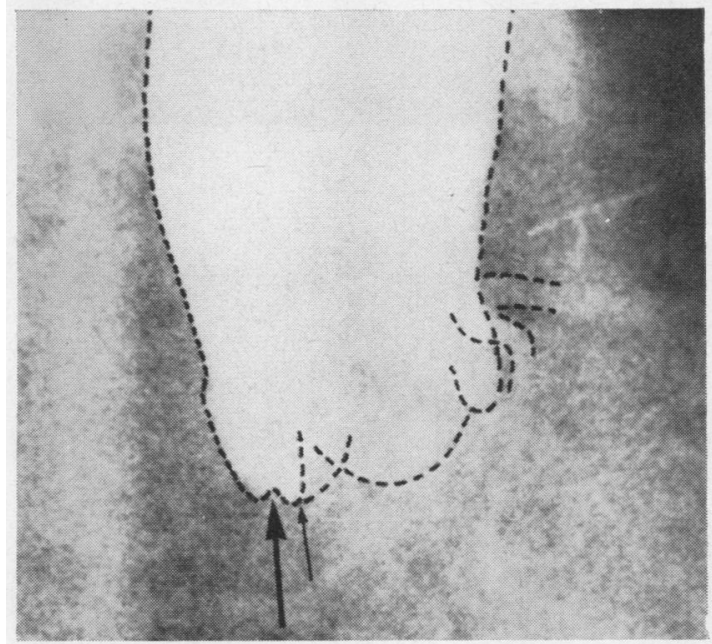

(b)

FIG. 7. Portion of cine frames in RAO view (9-in. intensifier): (a) Diastole. Slight ridge (arrow) in non-coronary sinus of Valsalva. Normal relative positions of left coronary $(L)$, right coronary $(R)$, and non-coronary $(N)$ cusps. $(b)$ Systole. The cusps open normally, the non-coronary cusp hingeing (small arrow) from a point close to ridge (large arrow). The ridge represents upper aspect of homograft aortic wall. 
had a very small aortic root and the commissural buttresses of the homograft had to be unevenly spaced to ensure good coronary artery filling; valve function was good, there being only a trivial peripheral leak through the right coronary sinus of Valsalva.

In all cases the homograft cusps appeared to be normally flexible and opened fully in systole, allowing a full-width non-opaque bolus to enter the aorta (Fig. 6b). In several patients the noncoronary cusp hinged from a point slightly central compared with normal (Figs $7 \mathrm{a}, \mathrm{b}$ and $8 \mathrm{a}, \mathrm{b}$ ), cor-

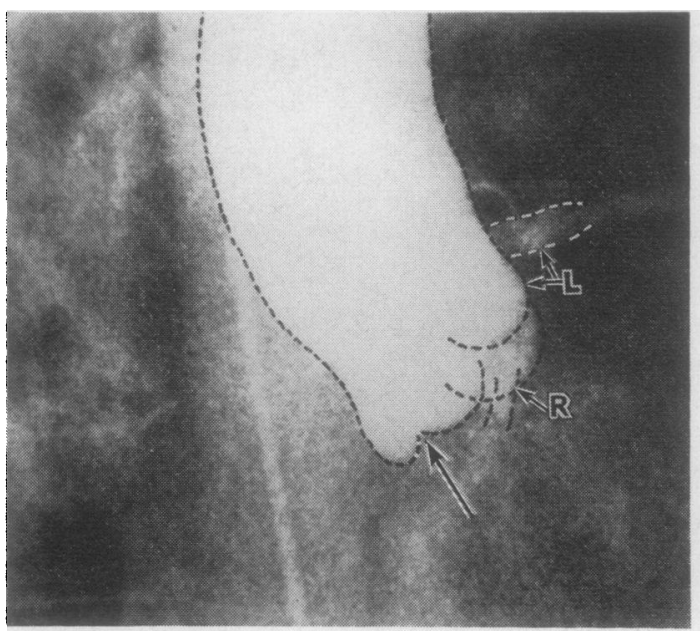

(a)

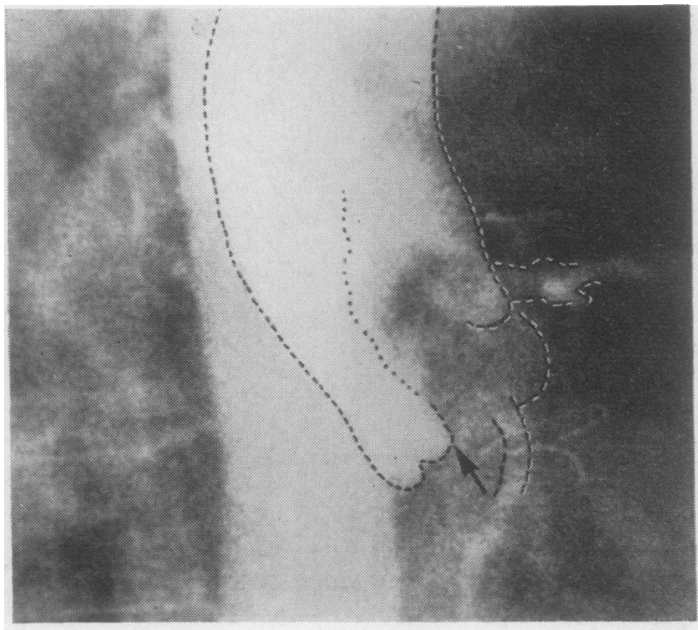

relating with the presence of a ridge in the noncoronary sinus of Valsalva as described above.

PERIPHERAL SPACE FILLING Some filling of the peripheral space was common, especially in the early part of the study before the introduction of vertical mattress sutures. Peripheral space filling was easy to recognize when the appropriate sinus of Valsalva was seen in profile (Figs 10 and 11). A crescentic layer of contrast lay below the upper suture line and appeared to extend up the aortic wall if one of the aortic buttresses, where the

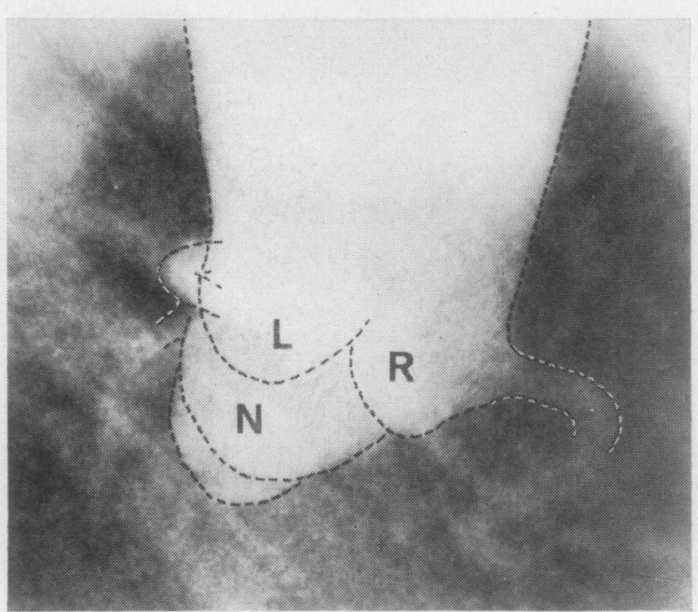

(c)

FIG. 8. A larger ridge in non coronary sinus: (a) Diastole $R A O$ (portion of cine frame). Relatively large ridge $\mathrm{N}$ (arrow) between non-coronary sinus and leaflet. Normal relationships of right $(R)$ and left $(L)$ coronary arteries and $O$ cusps. (b) Systole RAO (portion of cine frame). Non- $\omega$ coronary cusp hinges from a point (arrow) just central to the ridge. (c) Diastolic lateral cine frame (6-in. intensifier). Normally related cusps $(L, R$, and $N)$ with double contour of non-coronary cusp due to ridge profiled in $R A O$. 


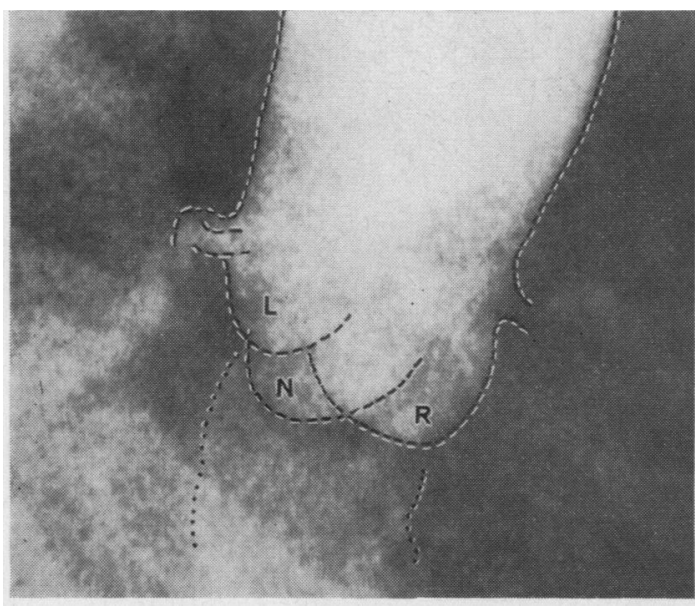

FIG. 9. Low position right coronary cusp. Diastolic lateral cine frame. Right coronary cusp $(R)$ is lower than noncoronary cusp $(N)$. Trivial central aortic incompetence was visible. No peripheral space filling.

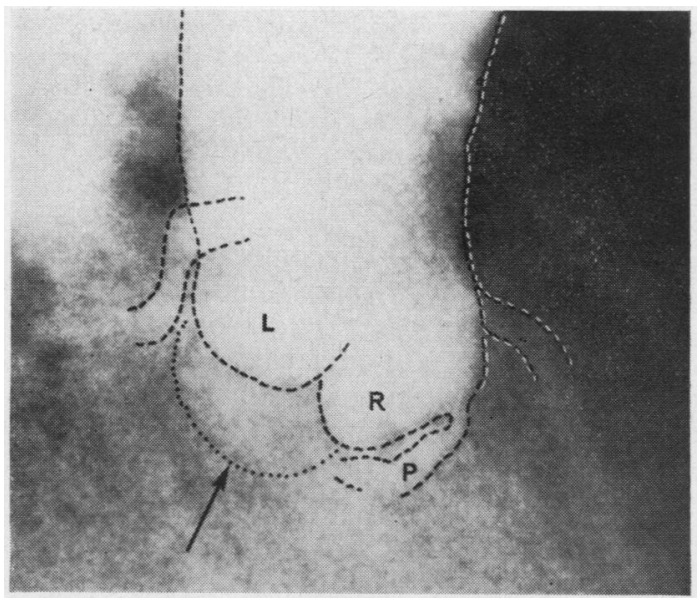

FIG. 10. Faint filling of non-coronary sinus. Diastolic lateral cine frame. The non-coronary sinus (arrow) filled poorly compared with left $(L)$ and right $(R)$ coronary sinuses (see text). Peripheral space $(P)$ filling can be seen beneath right coronary cusp.

peripheral space was widest, was profiled. One patient, studied before the period under review because of moderate aortic incompetence, had filling of the whole peripheral space, so that the valve cusps appeared to be surrounded by a cushion of contrast material (Fig. 12a-d). Sometimes the peripheral space filled in the form of a very narrow channel. A soft tissue plane, repre-

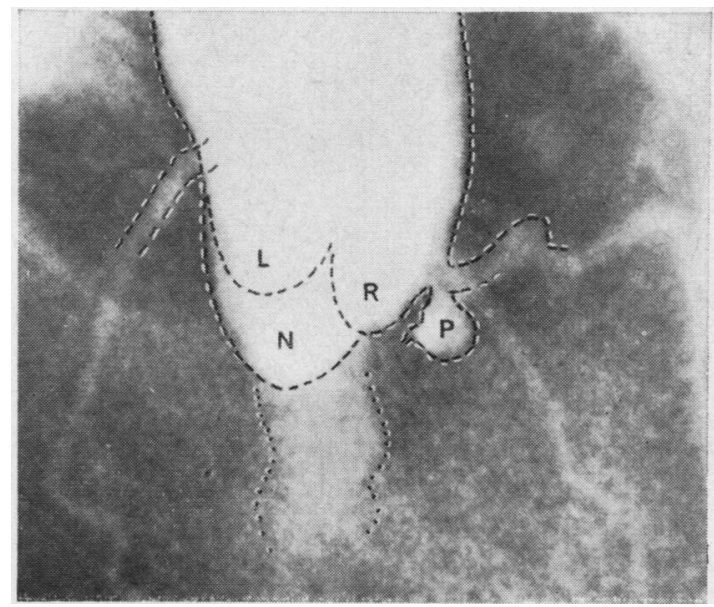

FIG. 11. Peripheral space filling, trivial leak apparently central. Diastolic lateral cine frame. A moderate pocket of peripheral space $(P)$ filling can be seen in relation to right coronary sinus $(R)$ and right coronary artery. The trivial leak appeared to be mainly central.

senting the donor aortic wall, always separated the filled peripheral space from the aortic lumen, except where suture line deficiencies were profiled (Fig. 13a-c).

\section{HOMOGRAFT AORTIC INCOMPETENCE}

The mechanism of peripheral incompetence was clearly seen in some patients. In diastole, contrast flowed from the sinus of Valsalva through a defect in the upper suture line (Fig. 13a). The peripheral space was thereby filled, and through another defect in the lower suture line (Fig. 13b) contrast reached the left ventricular outflow tract (Fig. 13c).

The presence of peripheral space filling seemed to be significant in the incidence of aortic incompetence, for every patient with visible peripheral space filling had some incompetence (Table IV). The degree of peripheral space filling, however, did not appear to correlate with the degree of incompetence, as this was trivial in many patients with moderate peripheral space filling. In about half the patients with incompetence and peripheral space filling, the leak appeared to pass through the peripheral space, and this was so in all three patients with moderate incompetence. In the other half, the leak appeared to be partly or wholly central (Fig. 11). Most of these were trivial leaks, only three patients having mild aortic incompetence. 


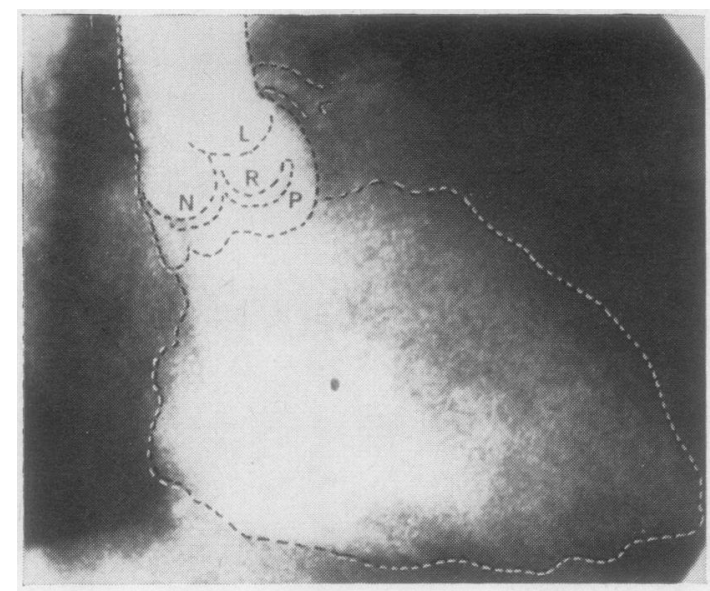

(a)

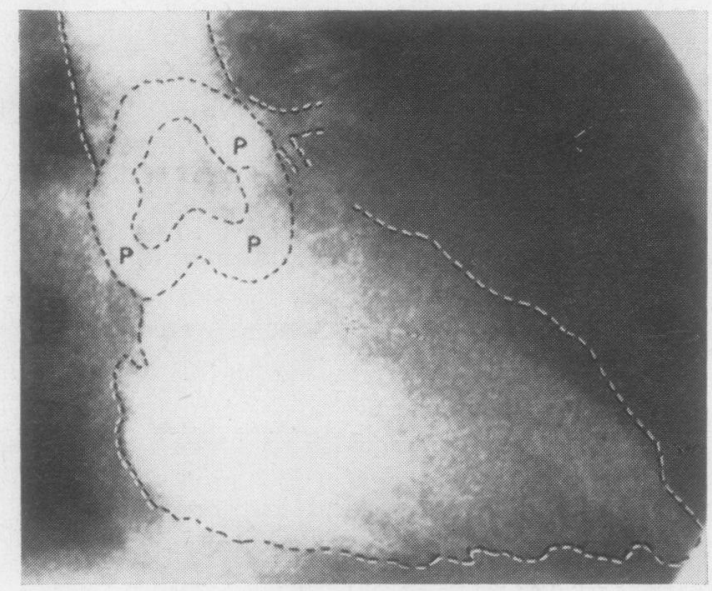

(b)

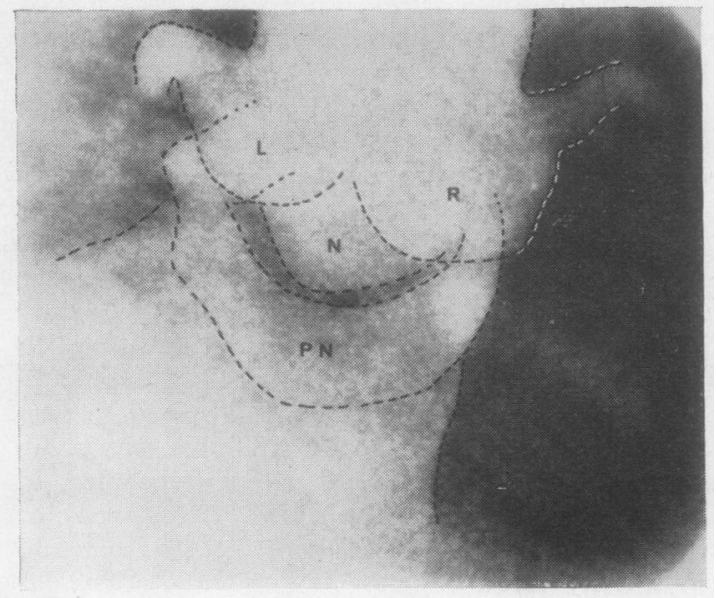

(c)

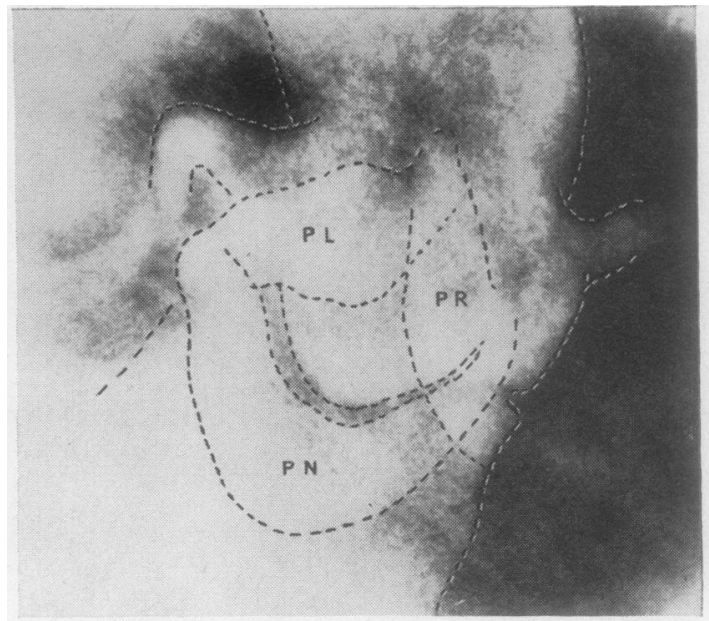

(d)

FIG. 12. Extensive peripheral space filling, moderate $\stackrel{\widehat{\partial}}{د}$ aortic incompetence. (a) Diastolic RAO cine frame. Peri- $\vec{Q}$ pheral space $(P)$ filling can be seen beneath right $(R)$ and $\mathscr{O}$ non $(N)$ coronary cusps. (b) Systolic RAO frame. The whole $\Theta$ peripheral space $(P)$ remains filled while systolic 'washout' $\square$ reduces contrast density in the centre. (c) Diastolic lateral cine frame. A wide crescentic layer of contrast. $(P N)$ beneath non-coronary cusp $(N)$ represents that portion of ${ }_{D}$ the filled peripheral space. (d) Systolic lateral cine frame. $\frac{}{\mathbb{}}$ During central 'washout' the peripheral space adjacent $\cong$ to the three aortic leaflets remains filled $(P N, P R, P L)$.

Eight patients had incompetence without demonstrated peripheral space filling (Figs 1a, b : $4 \mathrm{a}, \mathrm{b}$; and 9) and in these the leak was considered $\frac{0}{\mathrm{O}}$ to be central. Four had trivial leaks, presumably $x$ due to some imperfection in apposition of the 윽 cusps, three had mild incompetence, and one showed severe incompetence (Fig. $4 a, b)$, cusp rup- $O$ ture being suspected radiologically and confirmed at operation.

INCIDENCE AND DEGREE The incidence and degree of homograft incompetence revealed in the study $\widetilde{\sigma}$ are summarized in Table $\mathrm{V}$, the results in patients with preoperative calcific aortic stenosis or aortic incompetence as the dominant lesion being indi- $\omega$ cated. A completely competent valve was found more frequently in those with preoperative stenosis. Thirty-six patients $(71 \%)$ had no signi- $\overline{\mathbb{D}}$ ficant incompetence (grades 0 and 1$) ; 11(22 \%)^{+}$ had mild incompetence. Of the three patients with moderate incompetence, two had severe incom- $\frac{0}{0}$ petence preoperatively and were so symptomati- $\stackrel{\odot}{\mathcal{P}}$ cally improved by the operation that no further尺 action was indicated. The third, who had preoperative stenosis and was severely affected byo the homograft incompetence, required reopera-o 
tion. The patient with severe incompetence also required reoperation, when the suspected diagnosis of cusp rupture was confirmed.

EFFECT OF VERTICAL MATTRESS SUTURES The introduction of vertical mattress sutures divided the patients into two almost equal groups which are compared in Tables VI and VII.

Of the 27 patients studied before the use of vertical mattress sutures, only two had completely competent valves, though the degree of incompetence was trivial in over half the remainder. Only four patients $(15 \%)$ had no visible peripheral space filling.

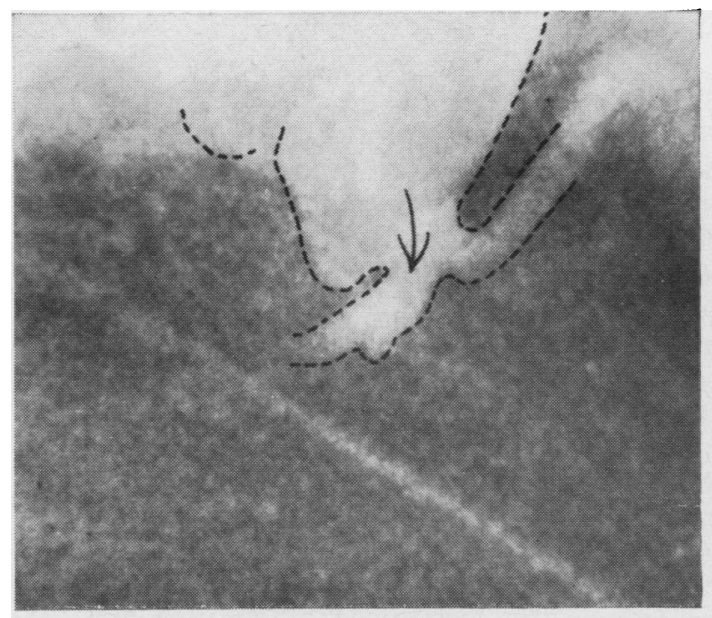

(a)

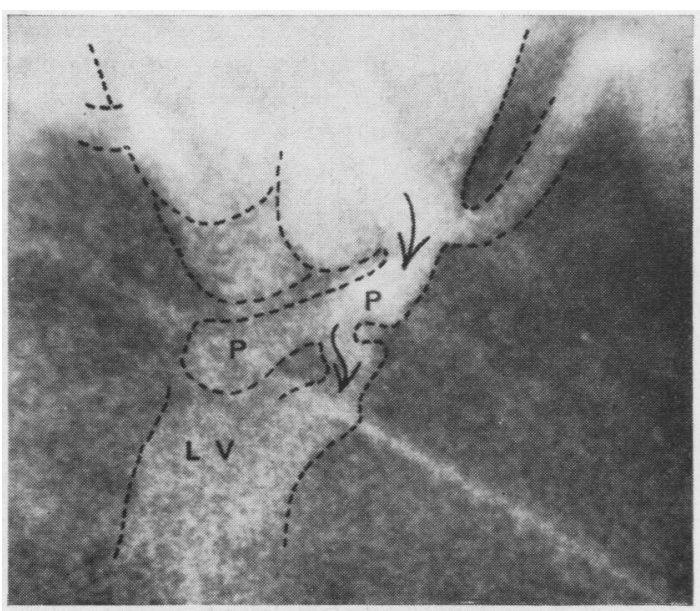

Of the 24 patients studied after the introduction of vertical mattress sutures, there were far fewer with haemodynamically significant incompetence, as one-third had completely competent valves and half showed only trivial incompetence. Peripheral space filling was also absent in 14 (58\%).

CLINICAL-RADIOLOGICAL CORRELATION The comparison of the radiological and clinical assessment of the degree of homograft incompetence is summarized in Table VIII. A close agreement was demonstrated; all the patients with significant (mild or more) incompetence who were assessed differently had been considered to fall near the

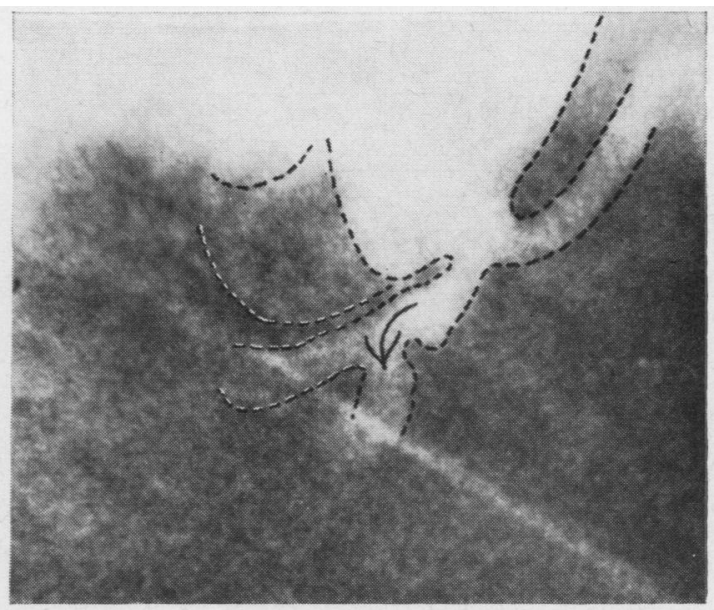

(b)

FIG. 13. Mechanism of peripheral leak. Portions of lateral cine frames. (a) Defect (arrow) in upper suture line allows contrast to flow into peripheral space from right coronary sinus of Valsalva in early diastole. (b) Two frames later (approx. 1/35 sec.) contrast passes through defect in lower suture line (arrow). (c) Three frames after (b) left ventricular outflow tract $(L V)$ is filling and peripheral space filling $(P)$ beneath right and non coronary cusps is advanced. 
T A B L E I V

INCOMPETENCE ACCORDING TO PRESENCE OR ABSENCE OF PERIPHERAL SPACE FILLING

\begin{tabular}{|c|c|c|c|c|c|c|c|}
\hline \multirow{3}{*}{$\begin{array}{l}\text { Peripheral } \\
\text { Space } \\
\text { Filling }\end{array}$} & \multicolumn{6}{|c|}{ Incompetence } & \multirow{3}{*}{ Total } \\
\hline & \multirow{2}{*}{ Type (when present) } & \multicolumn{5}{|c|}{ Cine Grade } & \\
\hline & & 0 & 1 & 2 & 3 & 4 & \\
\hline $\begin{array}{l}\text { Present } \\
\text { Absent }\end{array}$ & $\begin{array}{l}\text { Peripheral } \\
\text { Central ( } \pm \text { peripheral) } \\
\text { Central }\end{array}$ & $\begin{array}{r}0 \\
0 \\
10\end{array}$ & $\begin{array}{r}8 \\
14 \\
4\end{array}$ & $\begin{array}{l}5 \\
3 \\
3\end{array}$ & $\begin{array}{l}3 \\
0 \\
0\end{array}$ & $\begin{array}{l}0 \\
0 \\
1\end{array}$ & $\begin{array}{l}16 \\
17 \\
18\end{array}$ \\
\hline
\end{tabular}

T A B L E V

HOMOGRAFT INCOMPETENCE

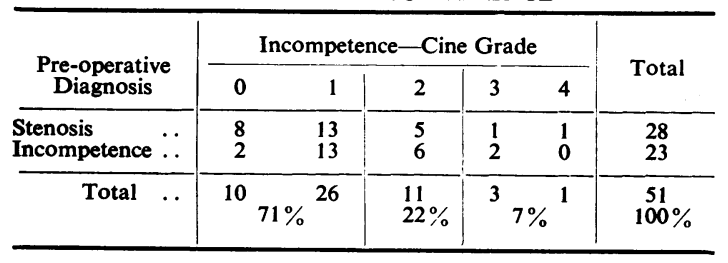

T A B LE V I

\begin{tabular}{c|cc|c|cc|c}
\hline $\begin{array}{c}\text { Vertical } \\
\text { Mattress }\end{array}$ & \multicolumn{5}{|c|}{ Incompetence-Cine Grade } & Total \\
\cline { 2 - 6 } Sutures & 0 & 1 & 2 & 3 & 4 & \\
\hline No & 2 & 14 & 8 & 2 & 1 & 27 \\
Yes & 8 & 12 & 3 & 1 & 0 & 24 \\
\hline
\end{tabular}

T A B L E V I I

\begin{tabular}{c|c|c|c}
\hline $\begin{array}{c}\text { Vertical } \\
\text { Mattress } \\
\text { Sutures }\end{array}$ & \multicolumn{2}{|c|}{ Peripheral Space Filling } & Total \\
\hline Absent & Present & \\
\hline No & 4 & 23 & 27 \\
\hline
\end{tabular}

T A B LE V I I I

CLINICAL-RADIOLOGICAL CORRELATION OF INCOMPE-

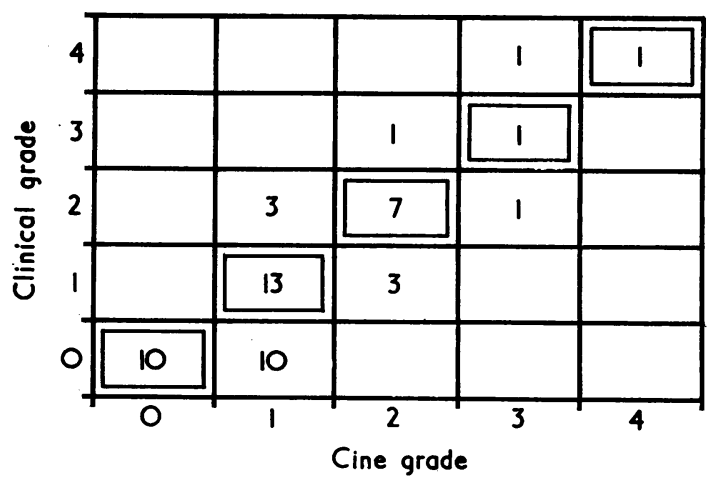

borderline in grading. There were 10 patients with no clinical evidence of incompetence who were shown radiologically to have a trivial leak, obviously of no haemodynamic significance. In no case where there was even transitory outlining of the left ventricular cavity was the incompetence silent. The 13 patients adjudged to have trivial incompstence by both methods all had unimpressive early diastolic murmurs but no other clinical evidence of incompetence. The one patient with clinically severe incompetence, yet radiologically graded moderate, had interstitial oedema on the chest radiograph and was undoubtedly severely affected by moderate run-off into a left ventricle which was hypertrophied and of small volume, the preoperative diagnosis having been aortic stenosis.

\section{DISCUSSION}

Aortography was performed in only $60 \%$ of patients surviving at the time of election for the study. The reasons for excluding approximately $40 \%$ (Table II) were in no way related to the function of the homograft aortic valve or to the symptomatic state of the patient. Clinically, the non-studied patients showed less aontic incompetence than those studied (Table III), suggesting that the incidence of incompetence in the whole group was less than that revealed by the study. Admittedly, 12 patients not studied were assessed at one or two months rather than three. The lesser incidence of incompetence in the excluded group may be related to the fact that most of these operations were performed by the two most experienced surgeons.

The radiological method of grading aortic incompetence by cine aortography as described in this paper is a subjective one to some degree, and there were the usual difficulties in assigning some patients to a category when they seemed to belong in the boundary region between two. The radiological criteria listed in Table I were evolved from the classification of Sellers, Levy, Amplatz, and Lillehei (1964), designed for application to largefilm serial angiocardiography. We have found the method reproducible and fairly easy to apply in this group of patients in assessing an isolated valve lesion. In the presence of mitral regurgitation or left-to-right shunt from the left ventricle, underestimate of aortic incompetence could result if allowance is not made for these additional lesions. In the group presently reported, however, such problems were not encountered.

The use of the RAO projection is of some importance, as this gives the best estimate of left ventricular cavity size and shape, the unseen trans- 
verse diameter being closely related to that demonstrated, and the long axial diameter well displayed (Greene, Carlisle, Grant, and Bunnell, 1967). We have found lateral and LAO projections less satisfactory for the grading of aortic incompetence, because the long axial diameter is foreshortened and our criteria are less easy to apply.

With few exceptions, the cine films were of good quality and we believe the method to be more sensitive than serial film angiocardiography in revealing small degrees of regurgitation, minute amounts of contrast being visible by virtue of their motion only and usually invisible in a single frame. The 'closing whiff' described in this paper should not be considered as incompetence, and some authors have even speculated that this is a normal phenomenon (Littmann, Dean, Crowley, Gilson, and Williams, 1961 ; Criley, 1968 ; Fabian and Abrams, 1968). It might be argued that any aortic root injection creates an abnormal situation, and that our method of injection, using a catheter with open end hole, might produce artefactual incompetence. However, a 'closing whiff' was seen after injection was completed in some patients when it clearly was not due to a catheter jet. It therefore seems more likely that it results from a minor disturbance of the normal mechanism of valve closure.

It must be emphasized that the trivial category is difficult to detect clinically because it is haemodynamically insignificant, and less precise radiological methods would have resulted in many of these patients being considered fully competent. The outflow tract filling was rarely dense; dense filling here was usually accompanied by at least faint or transitory outlining of the cavity below, and these patients were therefore classified as at least mild (grade 2). Therefore, in assessing the operation, it is important to consider the grade 0 and 1 categories together as 'no significant aortic incompetence' if a realistic appraisal is to result.

The cine grading of mild aortic incompetence, in line with the discussion above, is probably comparable with a serial film study which reveals only outflow tract filling, as outflow tract filling of any density was usually accompanied by outlining of the left ventricular cavity, often seen only while the cine is viewed in motion.

The separation of moderate from severe incompetence seems worthwhile, for it indicates the difference between a valve that is capable of maintaining some contrast gradient between aorta and ventricle during the injection, and a valve that offers so little resistance to retrograde flow that densities are similar, even during injection of con- trast above the valve. We have not observed incompetence of such severity that the ventricle is outlined more densely than the aorta (Sellers et al., 1964). This could occur if too rapid an injection were given in early diastole in the presence of a severe leak. A rate of $20-25 \mathrm{ml}$. $/ \mathrm{sec}$. ensures that the $40 \mathrm{ml}$. injection takes nearly two seconds, which enables the distinctions discussed above to be revealed as the injection continues during at least two diastoles at the rates usually encountered.

Filling of the potential peripheral space appears to be of prime importance in incompetence three months after homograft aortic valve replacement. The figures show that by partially obliterating this space and dividing it into compartments with three vertical mattress sutures, the incidence of incompetence was significantly reduced. The study has revealed that most of the trivial leaks, clinically detectable or silent, were accompanied by some filling of the peripheral space though there is suspicion that only about half actually took place through the periphery. Such minute distinctions are difficult even with multiple radiological views, and it may be impossible to determine the mechanism of the incompetence in many of the patients with trivial leaks. However, when the incompetence was important (moderate or severe) three months after operation, the leak. was nearly always peripheral. The only patient in this study with an important central leak was studied at five months, having suffered cusp rupture which rarely occurs within three months of operation.

It would be expected that the incidence of postoperat ve incompetence wou'd be least in patients operated upon by the surgeon most experienced in this operation, using the most recent technique. The group analysed in this paper had been operated on by six surgeons (three senior surgeons and three trainees) and the surgical technique was modified during the period of the review. A group of 19 patients operated on by the most experienced surgeon using only the current technique, including vertical mattress sutures, was therefore analysed. Nine of these patients were included in the main series, and the remainder were studied at a later date using the same criteria (Table II) for exclusion of some patients from aortography. Nine of the 19 had fully competent valves, and nine had trivial and one moderate aortic incompetence. No peripheral space filling was visible in 12 of the 19 patients, this group consisting of the nine with perfectly competent valves and three of those with trivial incompetence. Six of the seven patients in whom peripheral space filling was visible showed only 
trivial leaks, and only in three of them was it possible to see that the leak actually occurred through the peripheral space. In the seventh patient the leak appeared to be central rather than through the periphery. The grading in this patient, both clinically and radiologically, was near the borderline between mild and moderate, and chest radiographs showed a postoperative reduction in heart size.

In this special group, 18 of the 19 patients $(95 \%)$ had no significant incompetence. However, the results also appear satisfactory in the larger series, especially since the introduction of vertical mattress sutures, when 21 of $25(84 \%)$ had no significant incompetence.

It is certainly not easy, and probably technically impossible, to obtain a completely competent homograft valve in every patient, particularly when the valve has been preserved in Hank's nutrient medium, as the aortic remnant in such valves is rather soft. While not reported in this series, a comparison of the incidence of aortic incompetence in valves used in this way with those that had been freeze-dried shows that incompetence is much less common with freeze-dried valves (Barratt-Boyes et al., 1968). The same may well be true of deep frozen valves as used by Malm et al. (1967) and is almost certainly the case with formalinized heterograft valves (O'Brien, Clarebrough, McDonald, Hale, Bray, and Cade, 1967). Despite this minor disadvantage, we continue to prefer Hank's medium for storage, as freeze-drying results in tissue damage and increases the risk of late cusp rupture (BarrattBoyes et al., 1968). Of the 51 valves used in the studied group, all had been sterilized with betapropiolactone, five had been preserved by freezedrying, and 46 in Hank's nutrient medium.

Perfectly competent valves were more frequently seen when the preoperative diagnosis was aortic stenosis rather than dominant incompetence. Marked dilatation of the aorta and valve ring is more common in aortic incompetence than in aortic stenosis. Tailoring of the aortic root was introduced in December 1964 (Barratt-Boyes, 1965) to obtain a better fit between a large aorta and the homograft valve, as a homograft that is too small is most likely to suffer peripheral detachment and peripheral incompetence. As tailoring was used whenever necessary in the patients presently reviewed, it seems that some factor other than dilatation of the aortic root may be largely responsible. The more extensive débridement required in many patients with aortic stenosis and heavy valve calcification may promote better organic closure of the potential peripheral space in these than in the typical patient with aortic incompetence when heavy calcification is unusual.

The fact that the correlation between the clinical and the radiological assessment of the incompetence was good is of special importance and suggests that the clinical grading reported in earlier publications (Barratt-Boyes, 1964 ; BarrattBoyes et al., 1965; Barratt-Boyes, 1967) was reliable. Though no important discrepancies were revealed in this study, it must be mentioned that we have since encountered one case in which the left ventricle outlined faintly on cine angiography in the absence of a murmur.

With regard to the early postoperative findings, it is of interest that the clinical picture may alter in the first few weeks after surgery. Of the 51 patients studied, 29 left hospital without a diastolic murmur and eight of these $(28 \%)$ had developed murmurs at three months. However, the cine films showed only trivial incompetence in seven, and mild incompetence in one. These figures support the clinical impression that important peripheral leaks are apparent before hospital discharge.

The question remains whether leaks that are trivial or mild three months postoperatively will subsequently progressively increase. Clinical follow-up to date indicates that most patients are stable after three months. Progressive aortic incompetence after this time has always been due to cusp rupture or endocarditis (in those patients requiring reoperation or coming to necropsy) and not to progressive peripheral leak. The patient illustrated in Fig. 12a-d, who had extensive peripheral space filling with moderate aortic incompetence, emphasizes this point, for he had been clinically stable for two years following operation, and others with angiographically demonstrated peripheral leaks have been clinically stable for up to five years.

Comparison with prosthetic aortic valve replacement is difficult, as there is no similar unselected angiographic follow-up szries in the literature. Clinical assessment of aortic ball valve incompztence is probably unreliable, particularly with trivial or mild leaks, and we have experience of one patient with an aortic Starr-Edwards valve in whom severe incompetence was silent. It is probable that with current techniques of homograft valve preparation and insertion by an experienced surgeon, the incidence of incompetence is comparable to that with a ball valve prosthesis (Bristow, McCord, Starr, Ritzmann, and Griswold, 1964: Judson, Ardaiz, Strach, and Jennings, 1964 ; Herr, Starr, Pierie, Wood, and Bigelow, 1968). 


\section{REFERENCES}

Barratt-Boyes, B. G. (1964). Homograft aortic valve replacement in aortic incompetence and stenosis. Thorax, 19, 131.

- (1965). A method for preparing and inserting a homograft aortic valve. Brit. J. Surg., 52, 847.

(1967). Homograft replacement for aortic valve disease. Mod. Conc. cardiovasc. Dis., 36, 1.

- Lowe, J. B., Cole, D. S., and Kelly, D. T. (1955). Homograft aortic valve replacement for aortic valve disease. Thorax, 20, 495.

- Roche, A. H. G., and Cole, D. S. (1968). Aortic homograft valve replacement: a review of 511 patients with a late follow-up extending to 65 months. J. cardiovasc. Surg. (Torino). In press.

Bigelow, W. G., Trimble, A. S., Aldridge, H. E., Bedard, P., Spratt, E. H., and Lansdown, E. L. (1967). The problem of insufficiency following homograft replacement of the aortic valve. J. thorac. cardiovasc. Surg., 54, 478.

Bristow, J. D., McCord, C. W., Starr, A., Ritzmann, L. W., and Griswold, H. E. (1964). Clinical and hemodynamic results of aortic valvular replacement with a ball-valve prosthesis. Circulation, 29, Suppl. p. 36.

Criley, J. M. (1968). Personal communication.

Fabian, C. E., and Abrams, H. L. (1968). Reflux through normal aortic valves. Invest. Radiol., 3, 178.

Greene, D. G., Carlisle, R., Grant, C., and Bunnell, I. L. (1967). Estimation of left ventricular volum? by one-plane cineangiography. Circulation, 35, 61 .
Herr, R. H., Starr, A., Pierie, W. R., Wood, J. A., and Bigelow, J. C. (1968). Aortic valve replacement. A review of six years' experience with the ball-valve prosthesis. Ann. thorac. Surg., 6, 199.

Hoeksema, T. D., Titus, J. L., Giuliani, E. R., and Kirklin, J. W. (1966). Use of homografts for replacement of the aortic valve in man. Circulation, 34, Suppl. 3, p. 129.

Judson, W. E., Ardaiz, J., Strach, T. B. J., and Jennings, R. S. (1964) Postoperative evaluation of prosthetic replacement of aortic and mitral valves. Ibid., 29, Suppl., p. 14.

Littmann, D., Dean, D. C., Crowley, F. B., Gilson, I. T., and Williams, J. A. (1961). Clinical coronary angiography. Amer. J. Cardiol., $\mathbf{7}, 570$.

Maln, J. R., Bowman, F. O., Jr., Harris, P. D., and Kowalik, A. T. W. (1967). An evaluation of aortic valve homografts sterilized by electron beam energy. J. ihorac. cardiovasc. Surg., 54, 471.

Nelson, R. J., Mohri, H., Winterscheid, L. C., Dillard, D. H., and Merendino, K. A. (1967). Early clinical experience with homotransplantation of the aortic valve. Circulation, 35, Suppl. 1, p. 3.

O'Brien, M. F., Clarebrough, J. K., McDonald, I. G., Hale, G. S. Bray, H. S., and Cade, J. F. (1967). Heterograft aortic valve replacement: initial follow-up study. Thorax, $22,387$.

Ross, D. N. (1966). Aortic-valve replacement. Lancet, 2, 461.

Sellers, R. D., Levy, M. J., Amplatz, K., and Lillehei, C. W. (1964) Left retrograde cardioangiography in acquired cardiac disease: technic, indications and interpretations in 700 cases. Amer.J. Cardiol., 14, 437. 